\title{
Padrões de adoção, modos de uso e representações sobre tecnologia: usuários do CAQDAS no reino unido, em meados da década de 90.
}

Wilma C. Mangabeira", Raymond M. Lee" e Nigel G. Fielding"

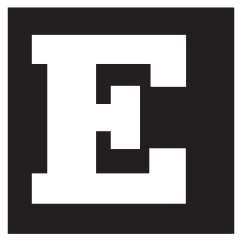

ste artigo trata dos usuários de CAQDAS (Computer Assisted Qualitative Data Software) no Reino Unido. Estamos especialmente interessados em compreender as transformações ocorridas desde a década de setenta, quando o uso de CAQDAS era limitado a um pequeno número de entusiastas e usuários de primeira geração.:

Na última década, muitas instituições de ensino superior do Reino Unido compraram pacotes do CAQDAS. Ao contrário da disponibilidade restrita dos programas no passado, muitos acadêmicos e estudantes de pós-graduação atualmente têm acesso ao CAQDAS, em redes nas universidades, através da oferta de cursos de treinamento e/ou apoio sistemático oferecido por alguns dos criadores de programas. Uma das questões abordadas neste artigo é como estão fazendo uso desta tecnologia, por um lado, o jovem estudante de pós-graduação em Ciências Sociais que é competente em informática e, por outro lado, o acadêmico mais velho e experiente.

Apesar da disponibilidade de, pelo menos, uma dúzia de pacotes de ampla utilização, as escolhas das universidades têm recaído freqüentemente em dois programas específicos. O que nos preocupa nesta tendência, é

\footnotetext{
*Wilma C. Mangabeira é pesquisadora na School of Social Science, Middlesex University em Londres. w.mangabeira@mdx.ac.uk

** Raymond M. Lee é professor no departamento de sociologia e ciência política na Royal Holloway University de Londres

*** Nigel Fielding é professor de Sociologia e co-Director do Institute of Social Research da University of Surrey
} 
que seu sucesso econômico, pelo menos no Reino Unido, pode acabar por traduzir-se no fechamento e na predominância de abordagens específicas e na limitação a certos estilos de análises. A maior comercialização na distribuição de programas também afetou o estilo da interação entre programadores. Se o tipo de interação, no final dos anos 70 e durante os 80, era caracterizado por colaboração e um fluxo relativamente livre de informações, hoje em dia, a orientação mais mercadológica gerou uma maior concorrência entre os programadores e o tratamento de informação como algo 'comercialmente sensível'.

Outra importante tendência a ser observada é o fato de que o crescimento significativo no número de programas nas últimas duas décadas foi seguido por uma grande sofisticação em seus recursos, em termos de tecnologia da informação, criando a possibilidade de aplicações novas e inesperadas. Uma outra tendência inovadora diz respeito ao processo de difusão de CAQDAS, que ao ultrapassar sua fronteira disciplinar tradicional - a das Ciências Sociais acadêmicas - alcançou não apenas a pesquisa aplicada, mas também outros campos como o de pesquisa de mercado, agências governamentais e organizações beneficentes. Como resultado disso, a comunidade de usuários de CAQDAS inclui agora um amplo espectro de profissionais.

Dadas essas importantes mudanças no emprego do CAQDAS, este artigo tem como um de seus principais objetivos o de identificar quem são estes novos usuários e o de descrever suas práticas. Um outro objetivo é o de compreender os novos padrões de adoção e as diferenças no modo de uso entre as primeiras gerações de usuários de CAQDAS e a atual.

O artigo se baseia em duas investigações empíricas sobre os usuários de CAQDAS. Apesar dessas pesquisas terem formatos e metodologias diferentes, acreditamos que uma complemente a outra.

Na primeira seção, apresentamos os resultados da pesquisa de Lee e Fielding, que foi baseada em entrevistas individuais e discussões de grupo com mais de 60 usuários de uma gama de programas qualitativos disponí- 
veis em meados dos ano 90. Outra fonte de informações foi fornecida por questionários de avaliação de mais de 1.500 pessoas que tomaram parte nos diversos programas de treinamento organizados pelo 'CAQDAS Networking Project'. As conclusões indicam que surgiram duas novas categorias de usuário de CAQDAS. Os que estão engajados na pesquisa aplicada e os que se dedicam à pesquisa em que o principal enfoque não são as Ciências Sociais.

Os autores relatam um aumento contínuo na demanda por treinamento em CAQDAS e tentam explicar a emergência deste padrão. O estudo também demonstra que os padrões de adoção por parte do segundo grupo podem explicar o modo típico de uso, que tende a utilizar recursos de gerenciamento de dados, ao invés daqueles mais analíticos e conceituais.

Por fim, o estudo de Lee e Fielding sugere que, embora a adoção de CAQDAS por novos tipos de usuários tenha um aspecto positivo, já que ajuda a consolidar uma nova ferramenta tecnológica, também traz motivos para preocupações, já que o perfil desses grupos é bastante diferente daquele do acadêmico de Ciências Sociais.

Na segunda seção, apresentamos a investigação de Mangabeira, que teve como base pesquisadores da área de Ciências Sociais e Humanas em um centro de pós-graduação de alto prestigio, em Londres. A escolha deste campo de pesquisa foi motivada pelo fato de que o Centro estava promovendo ativamente a divulgação de informação sobre CAQDAS e incentivando o uso destes programas, tanto por acadêmicos como por estudantes. Esse centro também cumpriu um importante papel no fornecimento de cursos de treinamento em dois programas CAQDAS. A pesquisa foi feita com base numa etnografia e apresenta algumas ilustrações de como a 'geração do usuário', em termos de idade, nível de conhecimento de computadores e tempo de experiência como pesquisador qualitativo pode explicar as diferentes formas nas quais CAQDAS tem sido aprendido e utilizado. Entre os resultados deste estudo apresentamos também o que pensam estes usuários sobre o potencial dos programas, em comparação com as análises manuais, assim como graus de 
certeza sobre o que CAQDAS 'pode fazer'.

As conclusões de Lee e Fielding, bem como as de Mangabeira, delineiam, de forma muito clara, diferentes categorias de usuários. Os primeiros autores identificam o 'especialista' bem como os usuários que trabalham em pesquisa aplicada. Eles distinguem, entre este segundo grupo, uma nova categoria de usuário, o 'usuário ingênuo'. Mangabeira identifica ainda outros grupos de usuários, nomeando-os respectivamente de: 'leais', 'reflexivos' e 'qualitativistas experientes'. Ao adotar o diagrama da 'curva de certeza' (Mackenzie 1990), apresentamos, na terceira seção deste artigo, uma descrição da distribuição de certeza a respeito de CAQDAS segundo esses diferentes grupos de usuários. Também projetamos este padrão de distribuição no futuro e concluímos apontando alguns dos desafios que se apresentarão para aqueles envolvidos na comunidade CAQDAS.

Dado o número limitado de estudos sobre usuários de CAQDAS, acreditamos que este artigo poderá enriquecer nossa compreensão sobre padrões de adoção de tecnologia ao apresentar um quadro de CAQDAS, quase duas décadas após seu surgimento, em meados dos ano 70. Além disso, a combinação de técnicas de pesquisa, entrevistas semi-estruturadas, trabalho de campo etnográfico, bem como observações de sessões de treinamento e informações obtidas nessas sessões permite a apresentação de uma descrição detalhada e complexa de como os usuários interagem com esta tecnologia e a representam.

Novos grupos de usuários: a adoção de CAQDAS por aqueles que desenvolvem pesquisa aplicada

Quando surgiram os programas qualitativos, eles eram baseados nas abordagens predominantes de análise. A principal metáfora era 'code-andretrieve', e não se esperava que o programa pudesse inspirar novas abordagens metodológicas. Entretanto hoje os pacotes sustentam cada vez mais 
novos procedimentos que se tornam inviáveis sem o uso do computador. Não podemos mais afirmar que o computador é simplesmente uma ajuda ao 'code-and-retrieve'. Ao mesmo tempo, à medida que os programas evoluem, o mesmo acontece com o padrão de adoção e possivelmente- de uso. Temos que revisitar uma pergunta para a qual já soubemos a resposta: "Quem são os usuários?" Só então poderemos responder a uma questão que vai mais além: "As práticas dos usuários mudaram?"

Esta seção apresenta os resultados de duas pesquisas diferentes-. A primeira é um estudo das experiências dos usuários de CAQDAS no Reino Unido, que desenvolvemos em meados dos anos 90. O estudo consistiu em uma série de discussões de 'grupos focais' com usuários de programas qualitativos. Por volta de 60 pessoas deles participaram. As discussões foram gravadas, transcritas e analisadas com a ajuda de diversos pacotes de programas qualitativos, principalmente Atlas/ti e NUDIST. O relatório completo desse estudo se encontra em Fielding e Lee (1998) ${ }^{1}$. Deve-se observar que a maioria dos participantes dos 'grupos focais' era de usuários de CAQDAS de primeira geração.

Dados desse estudo ajudam a sustentar algumas das afirmações dos entusiastas de CAQDAS, incluindo programadores, sobre o típico modo de uso desses programas em ambientes acadêmicos e aplicados. Consideramos tal pesquisa importante, pois permite acompanhar o desenvolvimento de uma inovação metodológica, e lamentamos que o nosso estudo permaneça sendo um dos únicos neste campo. O estudo indica quais as preocupações que os usuários trouxeram para CAQDAS. Qual o suporte que eles consideraram útil no (s) pacote (s) que adotaram e quais os problemas que encontraram. No entanto, cinco anos é um longo período na área de informática, dada a rapidez com que os avanços tecnológicos são introduzidos. Se, por um lado, identificamos uma certa continuidade, já que as mesmas questões chaves sobre adoção e uso são colocadas tanto pela primeira geração de usuários quanto por novos usuários, por outro, sabemos

1 Esta investigação foi financiada pelo UK Economic and Social Research Council - ESRC. 
que transformações significativas ocorreram nos últimos cinco anos.

Para obter evidências dessas transformações, utilizamos uma segunda fonte de dados, baseada na nossa experiência na direção do CAQDAS Networking Project, um centro nacional para informação e treinamento de programas qualitativos no Reino Unido. Utilizamos mais especificamente, dados sobre os participantes de seus programas de treinamento.

O CAQDAS Networking Project ${ }^{2}$ desenvolve um programa de treinamento desde 1994, e mais de 1.700 indivíduos já participaram em nossos eventos. Este projeto é desenvolvido de forma não - comercial, e treinamos em diversos programas e não apenas em um ou dois dos pacotes mais conhecidos. Mantemos dados básicos de todos os participantes de cursos e recolhemos questionários de avaliação depois de cada treinamento, os quais nos fornecem algumas informações sobre os antecedentes dos participantes e o uso que pretendem fazer do programa no qual os treinamos.

A partir destes dados, é possível afirmar que um novo padrão de adoção e uso está emergindo, introduzindo seus próprios problemas. Observamos, por exemplo, evidências crescentes de que os programas qualitativos estão atraindo, por razões instrumentais, usuários com nenhuma ou pouca formação em Ciências Sociais, cujo trabalho demanda aplicações puramente pragmáticas de automatizar a análise de dados qualitativos. Novas aplicações para métodos qualitativos estão sendo descobertas, e pesquisadores com pouca formação na área, oriundos de campos como medicina e saúde, estão sendo levados a aplicar métodos qualitativos. Este é um grupo que, semelhante aos estudantes novatos de Ciências Sociais, não possui formação anterior em métodos qualitativos no entanto em contraste com os estudantes, seus componentes demonstram um interesse puramente instrumental nesses métodos. É possível que os usuários deste novo grupo nem ao menos reconheçam que os dados que possuem são 'qualitativos' mas, ao invés disso, consideram-nos como texto, não exigindo qualquer trabalho interpretativo e não apresentando desafios maiores do que o de 
escrever um resumo adequado. Esses usuários se relacionam com as ferramentas para facilitar a análise qualitativa, não de uma perspectiva de um artesanato (como tem sido a tradição dos pesquisadores qualitativos), mas da perspectiva de um consumidor instrumental. Usamos a metáfora do 'modelo de ‘supermercado' para descrever uma forma particular de adoção de CAQDAS. Alguns dos produtos concorrentes em oferta são escolhidos devido à reputação transmitida boca-a-boca enquanto outros, o são por causa da grande promoção e excelente acabamento para colocação no mercado.

A partir das tendências, -descritas acima, podemos identificar o surgimento de dois importantes grupos de usuários, além dos acadêmicos. Há os usuários que trabalham em pesquisa aplicada, que têm formação em disciplinas das Ciências Sociais e Humanas, como Geografia Humana ou Sociologia, mas cujo envolvimento em pesquisa aplicada implica que uma parte de seu trabalho, e até mesmo a maioria dele, não foi conduzido nem publicado dentro de um contexto acadêmico.

O segundo grupo, inclui profissionais que não trabalham prioritariamente como pesquisadores, mas em outros campos como a medicina, que não têm formação na disciplina de Ciências Sociais e cujo envolvimento em pesquisa aplicada é secundário em relação a seu principal campo de trabalho. Por exemplo, já treinamos em CAQDAS vários médicos, que desejavam utilizá-lo para analisar históricos de pacientes com o objetivo de identificar meios de melhorar sua própria prática clínica. Ambos os grupos desafiam visões tradicionais de prática legítima de pesquisa, mas sugerimos que o segundo grupo é especialmente independente dos padrões normativos da pesquisa social e vulnerável às acusações de prática ingênua. Chamaremos este grupo de 'usuários ingênuos', mas, ao mesmo tempo, deixamos claro que nosso uso da palavra 'ingênuo' não tem sentido pejorativo, mas pretende simplesmente refletir sua falta de formação em Ciências Sociais.

Para dar uma indicação mais precisa da crescente importância desses novos grupos de usuários, podemos examinar os dados oriundos do CAQDAS 
Networking Project. O projeto presta uma série de serviços, entre eles: cursos de treinamento em programas; uma linha telefônica de apoio a usuários de CAQDAS; um grupo de discussão por e-mail; e seminários avançados para metodólogos, programadores e usuários. Entre junho de 1998 e junho de 2000, o projeto desenvolveu 76 atividades de treinamento. Entre os participantes dos cursos, durante esse período, havia profissionais de escolas de medicina e de odontologia, de uma instituição beneficente infantil, de um departamento do governo do Reino Unido que lida com a aquisição de armas e pesquisa relacionada à auto-defesa, de uma editora de Ciências Sociais, de um departamento do governo da Escandinávia responsável por estatísticas nacionais, de um departamento do governo do Reino Unido responsável por justiça criminal, de uma força-tarefa especial para a redução de arrombamentos, de uma faculdade agrícola nacional, de um instituto de saúde mental e de uma agência nacional responsável pela auditoria de despesas do governo do Reino Unido.

O fato de CAQDAS estar atingindo usuários oriundos de uma variedade tão grande de instituições é bastante gratificante, mas o que queremos enfatizar é que esses usuários não correspondem ao perfil típico do acadêmico de Ciências Sociais e têm-se tornado um elemento cada vez mais importante entre os participantes do treinamento em programas qualitativos. Embora não tenhamos realizado uma comparação sistemática, pensamos que a mesma tendência pode ser observada em outros centros de treinamento de CAQDAS. Seria interessante poder fazer tal comparação, caso os treinadores não considerem tais dados como comercialmente delicados.

Apesar desta limitação, podemos avançar neste ponto através da divisão dos participantes de cursos nas seguintes categorias: 


\section{CAQDAS Networking Project: Participants on Training Courses and Workshops}

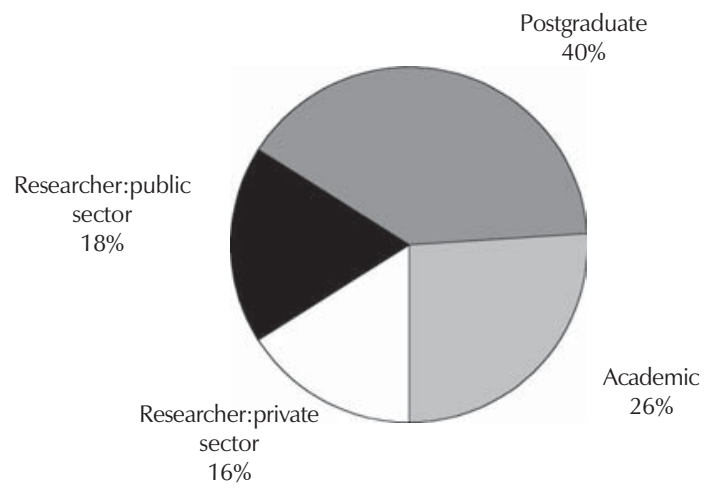

Mesmo que estimemos a proporção do penúltimo e do último grupos - pesquisadores com limitada/nenhuma formação - como a metade, isso ainda é 15 a $20 \%$ de nossos participantes.

Estes dados também podem ser comparados com o pano de fundo de uma demanda cada vez maior por treinamento em CAQDAS. O CAQDAS Networking Project funciona desde 1994. Em seus dois primeiros anos, o projeto treinou 347 usuários, sendo que praticamente todos eram acadêmicos de Ciências Sociais. No segundo período de dois anos, foram treinados 516 usuários, enquanto, nos dois anos até junho de 2000, o projeto treinou 854 usuários. Estes números totalizam 1.717 participantes. Cada período de dois anos registrou um grande aumento na demanda e, uma vez que o projeto começou a treinar usuários não-acadêmicos, a demanda no interior deste grupo aumentou.

Podemos atribuir este novo padrão a vários acontecimentos (Abbott, 1998). Um deles é a crescente aplicação de CAQDAS na análise de dados de 'grupos focais' nos setores de pesquisa de mercado e pesquisa social. 
Um outro elemento, é a aplicação cada vez mais comum de 'métodos múltiplos', onde métodos diversos, inclusive a análise de dados qualitativos, são empregados no design da pesquisa. Outro uso que também aumenta consideravelmente é a pesquisa na Internet, onde programas qualitativos são utilizados para analisar dados obtidos na rede.

Uma questão específica levantada pela utilização do CAQDAS pelo grupo de 'usuários ingênuos' é que, comparados com outros grupos de usuários com conhecimento prévio dos programas, estes parecem ter menor probabilidade de escolher com discernimento um programa de CAQDAS. A escolha pode resultar de um acaso a partir de contatos sociais, uma conversa com um conhecido em uma Universidade, uma casualidade etou propaganda de um curso através de um mecanismo de busca na web.

Em nossa pesquisa de campo, os usuários enfrentam dificuldades consideráveis com a pequena disponibilidade de programas, enquanto os candidatos a usuários que acabam por adquirir CAQDAS geralmente não o fazem através de uma comparação sistemática ou uma escolha discriminada, mas sim porque alguém em seu convívio social conhece um determinado pacote. No entanto, apesar dos problemas apontados acima, a recente expansão na comercialização de CAQDAS permitiu uma distribuição mais eficaz. Mas devemos observar também que apenas certos padrões de distribuição colocam os programas em mãos de usuários sem conhecimento prévio de CAQDAS. Graças a instrutores como Ray Maietta, Sylvana di Gregorio, Eben Weitzman, Susanne Friese, bem como o Networking Project uma introdução qualificada desses programas está tornando-se mais fácil de ser obtida. Não obstante, o treinamento permanece sendo, em grande parte, ad hoc e oferecido de forma não sistemática.

Para dar um exemplo, em um intercâmbio na lista de e-mailpara usuários de Atlas/ti, um candidato a usuário no Texas pediu treinamento, o que gerou uma oferta, condicionada à possibilidade de o indivíduo deslocar-se para Santa Bárbara. É uma longa distância, do Texas à Califórnia. Os pesquisadores no Reino Unido têm sorte pelo fato de o país ser pequeno, mas, mes- 
mo aqui, há lacunas na prestação desse serviço. Até onde temos conhecimento, o CAQDAS Networking Project permanece sendo a única instância de um centro nacional para programas qualitativos, assim como a única instituição que oferece treinamento no amplo espectro de programas.

Embora a questão sobre treinamento de usuários de CAQDAS tenha recebido pouca atenção na literatura, podemos deduzir certos princípios pedagógicos a partir do exemplo dos programas de metodologia quantitativa e análise estatística. Neste caso, a visão consensual é de que uma introdução básica sobre a lógica da análise estatística deve ser oferecida aos usuários antes que comecem a utilizar o programa. Da mesma forma, podemos argumentar que é pedagogicamente recomendável que as pessoas que forem novatas em métodos qualitativos devem ter alguma instrução geral prévia sobre a lógica do método qualitativo, os diferentes tipos de técnicas, e os tipos de análises que os dados qualitativos podem sustentar (Allat e Benson, 1991; Fielding e Lee, 1996).

Essa instrução não precisa ser elaborada ou prolongada, e muito se pode obter apenas com a leitura de uma bibliografia básica. Também não é necessário que sejamos rígidos na separação da instrução metodológica e de programas. Com um pouco de instrução básica, usuários em potencial podem obter o máximo de um programa. Após a introdução metodológica, não há problema em combinar a instrução em programas com metodologia, pois uma pode auxiliar a outra. Mas é necessário haver alguma compreensão inicial do método qualitativo para que se entendam os limites epistemológicos, práticos e processuais da pesquisa qualitativa. Embora este possa ser o caso quando se trata de formação metodológica em cursos acadêmicos, é questionável que seja o caso de treinamento em CAQDAS. Este tipo de treinamento acontece geralmente em cursos intensivos de curta duração concentrados em CAQDAS e com vistas à sua utilização em pesquisa aplicada, incluindo os casos nos quais uma disciplina de Ciências Sociais não está entre aquelas a que o pesquisador se dedica.

Pesquisas sugerem que este padrão de adoção também pode ser 
responsável pelo modo típico de uso, que tende a explorar o gerenciamento de dados, ao invés de utilizar recursos conceituais ou analíticos (Fielding e Lee, 1998).

Os usuários da área aplicada enfrentam menos problemas justificando a aquisição, do que os usuários acadêmicos de primeira geração, cujos supervisores e/ou colegas foram céticos ou até mesmo colocaram obstáculos-. No entanto, no caso dos usuários aplicados, seus patrocinadores parecem ser favoráveis ao uso de CAQDAS por razões de legitimação, mas enfrentam outros tipos de problemas. A estrutura da pesquisa aplicada tende a ter prazos rigorosos e exigências analíticas relativamente simples. Em nossa pesquisa com usuários, os pesquisadores deste meio reclamaram que as etapas iniciais de preparação dos arquivos com dados, tal como requerido por programas CAQDAS, tomavam um tempo desproporcional em relação à análise que o patrocinador desejava. Como resultado, alguns usuários achavam que estavam subutilizando o pacote. Estas reclamações refletem uma orientação instrumental e possivelmente expectativas não-realistas sobre o que CAQDAS pode fazer.

Os usuários - acadêmicos ou não-acadêmicos - esperam três coisas principais de CAQDAS: economizar tempo, tornar as análises mais minuciosas e possibilitar procedimentos analíticos que são manualmente impraticáveis. Entretanto não encontramos qualquer caso em que os usuários relatassem que o programa tenha economizado tempo de análise. Isso provavelmente não pode ser solucionado tecnologicamente. Codificação e análise intrinsecamente levam tempo (e assim deve ser). Não apenas os programadores não afirmam que o uso de CAQDAS é mais rápido, muitos deles enfatizam a necessidade de um trabalho minucioso no processo de codificação e refletem isso na "arquitetura" dos programas. Em relação á expectativa de que a análise venha a ser mais minuciosa e rigorosa, recorrentes testemunhos demonstram ser esta uma expectativa realista. Computadores não esquecem ou perdem coisas, eles sempre desenvolvem o mesmo procedimento da mesma forma e, se os usuários necessitarem ser 
lembrados de como foi realizada uma determinada operação, o programa sempre poderá ajudar a reconstruir a seqüência dos passos. Os usuários também foram bastante assertivos nos seus relatos quanto à capacidade de CAQDAS em lidar com grande volume de dados, de forma mais eficaz que os métodos baseados em papel.

Mas as opiniões com relação à sustentação de trabalho conceitual sofisticado não foram uniformes. Pesquisadores que desenvolvem pesquisa aplicada consideraram que o ritmo de seu trabalho não lhes dava tempo para interação criativa com recursos avançados. Às vezes, simplesmente não tinham tempo nem mesmo para codificar todos os dados, o que impunha sérios limites ao tipo de trabalho analítico possível. O valor de CAQDAS para eles era o de um arquivo eletrônico, ainda que alguns parecessem aliviar suas frustrações, prometendo a si mesmos que utilizariam recursos mais avançados no futuro, durante seu tempo livre. Em contraste com estes, os usuários acadêmicos foram geralmente entusiásticos a respeito dos recursos de reconceitualização, mas relataram problemas no aprendizado de sua utilização. Estudantes de pósgraduação mostraram-se mais entusiasmados sobre os recursos de conceitualização, o que pode indicar uma mente mais aberta com relação ao padrão de interação com os programas. No entanto, sabemos que, pelo menos até meados dos anos 90, mesmo os usuários acadêmicos faziam uso limitado dos recursos analíticos mais sofisticados oferecidos pelos programas.

A questão da subutilização de recursos de programas não é problemática no sentido de que alguns usuários estão usufruindo menos do que poderiam desses sistemas. A questão central é que usuários com formação limitada em método qualitativo provavelmente não estarão cientes dos critérios de validade e adequação analítica que habitualmente se aplicam em contextos acadêmicos. Sua apreciação do método qualitativo é limitada e definida pelo programa. Interpretações com fundamentações fracas sempre foram um problema da pesquisa qualitativa, mas, no trabalho acadêmiCo, há salvaguardas desenvolvidas pela comunidade. Na pesquisa aplicada, o usuário de CAQDAS pode ser o único membro de uma equipe que 
possui algum conhecimento sobre pesquisa qualitativa. Ainda assim, uma das razões para o crescente interesse em CAQDAS entre usuários de pesquisa aplicada, não-social, é a adoção cada vez maior da pesquisa qualitativa em instituições não acadêmicas, como por exemplo, em setores do Governo, em organizações médicas e empresariais (Abbott, 1998).

Entre outros problemas potenciais relacionados ao uso de programas, observamos os seguintes:

a codificação automática possibilita uma codificação de segmentos de texto rápida e unificada mas, ao mesmo tempo, pode acabar por substituir uma inspeção cuidadosa de cada segmento, antes que um código seja designado.

a complexidade de certos programas faz com que, às vezes, os usuários tenham apenas uma vaga idéia do que as operações específicas significaram para a sua análise como um todo.

uma 'quase - quantificação' dos resultados pode estimular análises numéricas aparentemente precisas, mas incorretas.

A evidência das experiências de nossos usuários é de que, quanto mais sofisticado o pacote, maior a probabilidades de os usuários identificarem um problema que pode ser chamado de 'o distanciamento do procedimento manual tradicional'. Mas os 'usuários ingênuos' podem não estar cientes de que há um procedimento manual do qual podemos distanciar-nos.

Os pacotes de CAQDAS variam quanto a abordagem de análise e de procedimentos analíticos. Por ordem de magnitude, foram relatados mais problemas com procedimentos analíticos em um pacote do que nos outros. Estes comentários não dizem respeito à dificuldade de executar análise utilizando o pacote, mas sim preocupações com relação à própria idéia de teste de hipóteses (theory building facility), uma questão muito debatida na literatura (ver, por exemplo, Kelle, 1995). Não é preciso tomar partido neste debate para sugerir que o que é interessante, quando nos confrontamos com um procedimento diferenciado como esse, é que estarmos cientes de que ele é diferenciado. Já os 'usuários ingênuos' podem aceitar procedimentos estranhos ou complicados com maior facilidade visto que não podem identificar o que são caracterís- 
ticas intrínsecas da pesquisa qualitativa.

Uma outra questão é sobre o tema do 'grau com que CAQDAS pode direcionar o processo de análise'. Comentários sobre esta questão por parte de entrevistados considerados como tendo conhecimento de CAQDAS, sugerem que eles são menos propensos a pensar que um programa pode afetar fundamentalmente o processo analítico. Em contraste, esta foi uma preocupação predominante em usuários com menos experiência. Na verdade, os comentários dos usuários mais especializados sobre os efeitos dos programas no processo analítico incluíram uma descrição de como o usuário gostaria de melhorar um pacote para que este fizesse 'o que eu realmente quero que faça'. Entretanto, enquanto os especialistas repudiavam a idéia de que o programa intrometia-se em seu próprio processo analítico, eles expressavam preocupações de que a adoção prematura de programas poderia levar os novatos a assumir uma abordagem específica de análise sem estarem totalmente cientes da gama de abordagens disponíveis.

De uma perspectiva pedagógica, o espectro de usuários de programas qualitativos inclui: pesquisadores experientes em trabalhos qualitativos, que são usuários novatos ou ingênuos de tecnologias de informação e consideram CAQDAS frustrante e mesmo ameaçador; usuários de tecnologias de informação que também têm conhecimento em metodologia de pesquisa, que consideram CAQDAS como uma ferramenta entre outras; e, finalmente, pessoas que não têm experiência, em qualquer dos campos. Para este último grupo, a principal questão parece ser o timming e a oportunidade de um treinamento metodológico em tecnologias de informação. Apenas este último grupo acredita haver riscos de CAQDAS 'apossar-se' de sua abordagem de análise. Se aprenderem os programas de forma isolada de um entendimento do método qualitativo, há o risco de que os recursos analíticos no pacote de sua escolha passem a representar, para eles, 'análise qualitativa'.

Na medida em que CAQDAS permite resultados numéricos - como a freqüência de códigos - a utilização destes programas tende a dirigir a atenção analítica para as regularidades e para códigos que podem ser conta- 
dos. Entre as operações mais fáceis na maioria dos pacotes está a contabilidade da ocorrência e recorrência de determinados códigos, podendo haver uma tentação de dar-se por satisfeito com a contagem, ao invés de examinar os segmentos de textos originais. Qualquer um que tenha começado a fazer inferências a partir de contagens e depois examinou os próprios dados irá verificar quão freqüentemente essas inferências são resultado da desordem daqueles dados e não da existência de fato de uma recorrência.

Uma experiência frustrante como a descrita acima deveria servir de alerta aos usuários com relação à importância da codificação precisa e as estratégias de buscas sistemáticas. No entanto, para reconhecer isso, é necessário que se entenda de princípios interpretativos, ao invés de simples contagens de coisas que são vistas como semelhantes. Colocada frente a uma disjunção, a prática rigorosa exige que o pesquisador revise o esquema de codificação. Isso é trabalhoso e desafiador, e pode haver uma tentação de não revisar códigos e passar por cima de contradições. Parece importante, portanto, que os novatos entendam as premissas básicas da análise qualitativa, antes de terem experiência com programas. Um instrutor de CAQDAS comentou que:

(...) com pesquisadores experientes é realmente possivel discutir por meia hora no telefone, sobre quais os tipos de dados que eles têm e... que tipos de perguntas eles deveriam fazer sobre seu programa e até onde os programas que usam Ihes trazem vantagens mas... se você conversar com um pesquisador menos experiente ... muitas vezes eu acabo sendo tomado por perguntas básicas sobre a forma com que eles coletaram seus dados e suposiçóes que estão fazendo sobre como deveriam interpretá-los, que me parece que deveriam ter sido reso/vidas muito antes de se chegar ao 'sistema de indexação'. 
Pode também ser o caso de que a pressão dos prazos sob a qual alguns usuários não-acadêmicos trabalham, conspire contra a possibilidade de o usuário construir uma base segura de análise. Pode haver pressões para não codificar, ou mesmo para não inserir todos os dados, bem como pressões contra codificações sistemáticas ou insuficientemente precisas. Podemos tomar como exemplo um de nossos 'grupos focais'. Um entrevistado reclamou que o volume de dados obstruía a análise:

(...) e tem uma quantidade enorme deles (de dados), acho que é demais (...). E pensei "o que será que eles (os entrevistados) estão pensando sobre $(X)^{\prime \prime}$, aperte o botão, e saem em torno de 8.000 folhas, e eu tenho que saber exatamente o que eu quero.

Ao conversar com este usuário, soubemos que o sistema de codificação do pesquisador não fazia qualquer distinção entre diferentes grupos na amostragem da pesquisa e que códigos únicos haviam sido aplicados a páginas inteiras de dados de entrevistas. Quando um entrevistado "especializado" sugeriu uma forma de determinada 'busca' (search or retrieval facility) poder ser utilizada para redução de dados e para destacar segmentos de dados que fossem analiticamente relevantes, a resposta foi que isso ainda não resolveria o problema, já que os dados não haviam sido completamente transcritos e inseridos no pacote. Vale a pena observar que isso poderia ser um exemplo de como CAQDAS pode expor práticas ineficientes de trabalho que permaneceriam escondidas sob as técnicas manuais que caracterizam a abordagem tradicional.

Uma outra questão é de como as tradições analíticas diferenciadas e tipos diferentes de pesquisa têm um impacto na adequação de CAQDAS. Um pesquisador de políticas sociais aplicadas comentou sobre a pressão dos prazos e a utilização de programas: 
Sociologias, Porto Alegre, ano 3, no 5, jan/jun 2001, p.20-57

Você me perguntou porque nós desistimos, e isso aconteceu quando chegamos à fase de 'recortar e colar', foi o número de páginas impressas que me deixou assustado. Eu não estava realmente preparado para isso, sabe como é... tínhamos 88 entrevistas, mais as notas de campo (...) Chegamos ao ponto em que dissemos que não podíamos codificar mais, criamos mais de 50 (códigos) (...). E temos que começar a analisar. Dissemos, 'certo, vamos começar com alguma coisa simples, temos todos estes exemplos com apenas um código e o material impresso era DESSA grossura (abre muito os braços). Um código entre os outros 50 códigos, e isso sem fazer qualquer aninhamento' de códigos ou cruzamento de códigos. E também sem utilizar operadores booleanos: sem qualquer ' $e$ ' $e$ 'mais'; naquele momento pensamos: 'meu Deus'! Tudo aquilo por fazer e ainda se tem que ler tudo novamente!

Outro entrevistado afirmou:(...) é uma coisa dinâmica, interativa, você só codifica de novo e descobre que tem partes levemente menores e as codifica, sabe como é, desmembra. Leva tempo. Entretanto o pesquisador de políticas não tinha esse tempo, de forma que nunca colheu os benefícios do trabalho preliminar. Uma proporção considerável (talvez $60 \%$ ) de nossa amostragem testemunhou um padrão de uso semeIhante, com CAQDAS sendo utilizado principalmente para gerenciamento de dados. Trata-se do que outro usuário chamou de 'análise básica', como 'contagens de freqüência, muito básicas'. 
Para os que se dedicam à pesquisa aplicada e à pesquisa cujo foco principal não são as Ciências Sociais, CAQDAS tem alguns benefícios claros. Para os pesquisadores, esses benefícios incluem capacidade de gerenciamento de dados inquestionavelmente maior do que os métodos baseados em papel, possibilidade de práticas de análise ordenadas e passíveis de acompanhamento e recursos que lhes possibilitam extrair o máximo de seus dados. Para o público pesquisador, os programas qualitativos aumentam a legitimidade da pesquisa qualitativa e, ainda mais interessante, apontam para um maior envolvimento na pesquisa, ao invés de considerá-la um produto que ele simplesmente consome. Mas à medida em que os padrões dos usuários se afastam das origens de CAQDAS nas Ciências Sociais acadêmicas, precisamos assimilar as novas formas nas quais o programa está sendo aplicado para ajudar os novos usuários, evitando as ciladas que são tão familiares a quem tem formação em pesquisa qualitativa.

O que há de social no uso de um programa? Um estudo etnográfico da adoção e uso de CAQDAS em uma faculdade de ciências sociais ${ }^{3}$

Esta seção apresenta algumas das conclusões de um estudo etnográfico de usuários de CAQDAS. A pesquisa foi desenvolvida em meados dos anos 90 e envolveu seis meses de trabalho de campo em um prestigioso Centro de Ciências Sociais em Londres ${ }^{4}$.

Embora a difusão da informação com relação a CAQDAS venha ocorrendo neste Centro desde o final dos anos 80, através de apresentações

$3 \mathrm{O}$ título desta parte é uma referência direta a um debate conhecido sobre interpretativismo restritivo ou radical, claramente exposto no artigo What is Social About Being Shot, in Grint e Woolgar (1992).

4 Esta pesquisa foi parte de um projeto mais amplo intitulado, 'The Effects of Technology on Research Culture: the case of computer support for qualitative data analysis'. Este projeto foi financiado pelo Higher Education Funding Council e desenvolvido durante o trabalho de Mangabeira no Centre for Research into Innovation, Culture and Technology (CRICT), Brunel University. 
esporádicas por parte de alguns programadores, uma política ativa de promover a adoção e uso de programas deste tipo é mais recente. Essa política coincidiu com a criação de um Instituto de Metodologia, que ensina abordagens qualitativas e quantitativas, e com a instalação em sua rede de dois programas CAQDAS. O Centro também fornece cursos de treinamento freqüentes a estudantes e funcionários, bem como aos interessados de qualquer faculdade na Universidade de Londres ${ }^{5}$.

A estrutura teórica que informou esta pesquisa é a perspectiva 'construtivista', que sugere que a assimilação e o impacto da tecnologia não são um reflexo das chamadas 'qualidades inerentes' de uma dada tecnologia, mas, ao invés disso, dependem do contexto social e cultural de sua produção e uso. Não se deve tomar o significado de um artefato por si só, mas sim estudar de que forma as tecnologias são moldadas e adquirem seu significado na interação social.

Informados por essa teoria, queríamos ${ }^{6}$ acompanhar as novas dinâmicas sociais criadas como resultado da política ativa de promoção e encorajamento do uso de CAQDAS. As perguntas que tentamos responder incluíram, as seguintes: por que alguns dos acadêmicos e pós-graduandos adotaram CAQDAS? Quais eram as expectativas e representações acerca desta tecnologia? Como os usuários interagem com CAQDAS e quais eram os modos típicos de uso?

Como acontece em qualquer etnografia envolvendo o estudo de tecnologia, enfrentamos vários problemas específicos, a começar pela própria definição do que seria o 'campo etnográfico' a ser estudado. Outro

\footnotetext{
5 Embora não tenhamos evidência sólida para afirmar, parece bastante provável que uma política mais agressiva de metodologia de ensino e introdução de CAQDAS no Centro estava relacionada a pressões de parte do ESRC. Este organismo de financiamento de pesquisa do Reino Unido, que estava precisando de fundos e disposto a mostrar ao governo que estava buscando reformas, expressou sérias preocupações na época, em relação às baixas taxas de finalização de PhDs, bem como com o tempo levado pelos estudantes para obtenção de seus diplomas. Mais além, havia questionamentos em relação à qualidade do apoio oferecido ao pós-graduandos, e isso estava relacionado especificamente à falta de metodologia formal de ensino. Como resultado disso, no início dos anos 90, todas as instituições de ensino superior do Reino Unido com programas de Ciências Sociais tiveram que oferecer pelo menos um curso de metodologia para quem estava matriculado em cursos de Mphil e PhD.

6 Vale a pena observar que as conclusões relatadas nesta parte originaram-se de minha pesquisa individual e não eram parte do trabalho de Lee e Fielding. Entretanto, por razões de estilo, escolhi adotar o plural majestático, ao invés de escrever na primeira pessoa.
} 
problema foi o de construir instrumentos metodológicos para observar e interpretar as interações dos usuários com esta tecnologia ${ }^{7}$.

Nos estágios iniciais do trabalho de campo, encontramo-nos buscando um 'local', algo concreto que nos possibilitasse dizer: "sim, agora entramos no campo". Tínhamos uma visão idealizada dos usuários de CAQDAS interagindo com a tecnologia e respondendo a todas as nossas perguntas. Na realidade, o que encontramos foi usuários trabalhando isoladamente em suas salas e, às vezes, até mesmo fora da faculdade. Não havia um 'local de pesquisa' no sentido objetivo do termo.

Após um certo tempo, todavia, foi possível identificar um 'campo': não era um local, mas um momento analítico, um período de tempo no qual o etnógrafo iria para a faculdade e circularia, participando de reuniões de usuários de NUDIST, ATLAS/ti, sessões de treinamento de CAQDAS e seminários de metodologia. Tomava-se muito café na cantina e, de vez em quando, faziam-se entrevistas formais com alguns usuários.

A pesquisa também incluiu acompanhamento diário dos intercâmbios que ocorriam em vários das redes eletrônicas do CAQDAS na Internet.

Esta etnografia também trouxe à tona muitas questões interessantes em relação às variadas identidades e papéis da pesquisadora com relação à pesquisa, introduzindo toda uma discussão sobre 'reflexividade'. Embora não possamos, aqui, deter-nos nestas questões em detalhes, vale a pena observar que os limites entre pesquisador e grupo pesquisado ficaram confusos, pois eles eram ao mesmo tempo entrevistados e colegas (cientistas sociais como nós). Mesmo que tentássemos, haveria pouco espaço para afirmação de autoridade ou grau superior de conhecimento em CAQDAS.

Estes entrevistados estavam não apenas curiosos para saber de que tratava a pesquisa, mas também leram a proposta e discutiram a sua estrutura teórica. Além disso, pediram que apresentássemos um artigo com as conclusões iniciais, o que provocou uma discussão bastante animada.

Questões relacionadas à reflexividade, apareceram novamente na

7 Para excelentes debates sobre os tipos de problemas encontrados por etnógrafos da tecnologia, ver Cooper et al (1993) and Hine (1994). 
fase de análise de dados. Quando lemos e codificamos as transcrições perguntamo-nos - da mesma forma como havíamos feito com nossos entrevistados - como procedemos quando fazemos análise qualitativa. Isso nos suscita, é claro, um ponto central: deveríamos utilizar um programa CAQDAS para analisar os nossos dados? Em caso afirmativo, qual e por quê? Uma forma de resolver estas questões poderia ter sido no mesmo caminho de Lee e Fielding, que analisaram seus dados com a ajuda de vários pacotes de programas qualitativos, principalmente ATLAS/ti e NUDIST.

Decidimos tomar um caminho radicalmente diverso e fazer uma análise manual, pelo menos nesta fase. Esta decisão se baseou na idéia de que o uso de um ou vários pacotes CAQDAS pelo etnógrafo exigiria necessariamente a abordagem de várias questões reflexivas, tais como o fato de que o etnógrafo, um usuário de CAQDAS no momento de analisar os dados, estava escrevendo sobre usuários de CAQDAS, e assim por diante. Poderá ocorrer que, no futuro analisemos nossos dados pela segunda vez, fazendo uso de CAQDAS para escrever um artigo diferente.

Nas páginas seguintes, apresentamos as conclusões da pesquisa, concentrando-as em três temas principais: 1. a dinâmica social da adoção de CAQDAS; 2. como o conceito de 'gerações' pode explicar modos diferenciados de uso de CAQDAS e a classificação de diferentes grupos de usuários; e 3. como diferentes grupos de usuários exibem graus de certeza ou incerteza do que CAQDAS pode fazer e quão eficaz eles podem ser.

\section{Dinâmica social da assimilação de CAQDAS}

Como já mencionamos acima, apesar do suporte 'institucional' à adoção de CAQDAS, alguns usuários, especialmente estudantes de $P h D$, tenderam a fazer parte da mesma rede informal assim como a estar ligados aos mesmos supervisores. Isto revela que a difusão de informação a respeito de CAQDAS não é generalizada e ainda é uma prática restrita nesta 
escola. O pertencimento a uma mesma rede social de estudantes de pósgraduação, bem como intercâmbios informais entre acadêmicos, também cumpriram um papel importante na explicação de por que o usuário veio a adotar um dos programas de CAQDAS.

A explicação mais recorrente encontrada para explicar por que se veio a utilizar CAQDAS especialmente entre os estudantes de pós-graduação, foi a de que CAQDAS permitiria acelerar o estágio da análise de dados de seus projetos de pesquisa com grandes conjuntos de dados, tanto em relação a número de casos, quanto ao número de entrevistados ou ao número de documentos/recortes de jornal, como se pode observar nas seguintes entrevistas:

Ma: (comecei a utilizar o programa) porque sabia muito bem que não poderia dar conta desta grande quantidade de dados e que haveria problemas sérios em minha análise se eu não usasse um programa como esse (...) podia ver o programa trabalhando para mim, ajudando-me a ordenar meus dados (...) eu tinha que ser minuciosa na análise.

$\mathrm{NI}$ : (Comecei a usar) por causa do grande volume de entrevistas. Sabia que não conseguiria fazer à mão. Comecei a fazer um sistema manual de codificação, mas me perdi.

Lu: Comecei a usar o programa depois da oficina do "programador $Y$ ". Naquela época, eu estava procurando um programa, porque estava fazendo à mão e era um pesadelo. Quando eu vio 'programa Y', eu pensei: é isso!

Um dado interessante é que o investimento de tempo necessário para aprender o programa e resolver os problemas encontrados pelos usuários ao tentar entender e aplicar os programas não resultou em economia de tempo. A conclusão de algumas teses de $\mathrm{PhD}$ e relatórios de pesquisa têm sido atrasadas como resultado direto dos problemas encontrados no uso de pacotes CAQDAS.

Independentemente desse fato, um número significativo de entrevistados relutou em abandonar o pacote e desenvolver análise manual de 
dados. Isso pode indicar que existem várias questões relacionadas à adoção de programas que não são reveladas no argumento de 'economia de tempo.' Poderia afirmar-se que a adoção de CAQDAS por este grupo de pesquisadores qualitativos tem um efeito 'performático' no sentido Woolgariano (1996) do termo. Isto é, ao se utilizar uma tecnologia com todo o simbolismo de 'rigor' e 'robustez' associados a ela, estamos acrescentando um nível adicional de credibilidade ao nosso trabalho acadêmico.

A referência a grandes conjuntos de dados para justificar a adoção de CAQDAS, como é ilustrado por estas citações e mencionado freqüentemente por outros estudantes de pós-graduação, pode ser interpretada como revelando inexperiência com relação à metodologia qualitativa.

Quando pedimos aos entrevistados para que detalhassem a natureza de seus conjuntos de dados e, a lógica metodológica que justificasse a sua coleta, assim como o seu tamanho, as respostas indicavam uma vaga relação com as perguntas das pesquisas e com seu design. Em outras palavras, o tamanho dos conjuntos de dados não estava relacionado a idéias sobre amostragem teórica, nem à de redundância, mas parecia que esses dados haviam sido coletados em função de uma percepção do que eram as exigências do Centro, "para que pudesse ser considerada uma pesquisa de $P h D^{\prime}$. Essa questão parece um exemplo claro de 'conhecimento local implícito' (Geertz 1983), já que não havia qualquer instrução formal do Centro sobre a extensão de investigações empíricas e, ainda assim, muitos dos pós-graduandos entrevistados revelavam ter uma idéia comum sobre as alegadas exigências de tamanho.

Essa conclusão interessante reforça a afirmação feita por Lee e Fielding na primeira seção, sobre a necessidade de que novos usuários compreendam as premissas da análise qualitativa antes de utilizar qualquer programa CAQDAS. O que perece ser específico deste grupo, no entanto, diferentemente de alguns usuários de Lee e Fielding, é que eles estão inseridos num contexto acadêmico e, portanto, socializados em certos padrões normativos de pesquisa em Ciências Sociais e Humanas, apesar de um pouco inexperientes em questões metodológicas de pesquisa empírica. 


\section{Como o conceito de 'gerações' pode explicar diferentes modos de uso de CAQDAS}

Como já foi mencionado anteriormente, ao contrário de outros grupos de usuários de programas CAQDAS, os usuários da técnica neste estudo são, eles próprios, da área de Ciências Sociais e Humanas. Este fato levanta questões interessantes de aprovação ou rejeição dos programas, percepções sobre a eficácia de CAQDAS, bem como por que alguns usuários fazem uma reapropriação dos programas, ao passo que outros não a fazem.

O caráter específico desta comunidade de usuários nos permite levantar a hipótese de que esses usuários teriam maior probabilidade de exercer algum nível de reflexividade em sua própria avaliação e uso do programa. Nossos dados sugerem que o grau em que os usuários são reflexivos sobre o uso de programas e exercem flexibilidade interpretativa pode ser explicado por dois fatores sociais:

a geração dos usuários (idade, nível de conhecimento de computação e experiência anterior como pesquisador qualitativo);

experiência prévia com outros programas CAQDAS.

A geração dos usuários parece ser um conceito poderoso para entender suas representações e seu uso de CAQDAS. É possível dizer que quanto mais jovem o usuário, mais conhecimentos de computação ele tende a ter. Esta experiência prévia com computadores e programas diferentes (mas não com CAQDAS) permite uma interação 'mais segura e menos ameaçada' com o programa, ultrapassando facilmente os estágios iniciais de formatação e entrada de dados e superando rapidamente os problemas 'técnicos'.

No entanto, apesar dos altos níveis de conhecimentos de computação e das representações a respeito de CAQDAS como sendo uma tecnologia que não ameaça, a avaliação recorrente entre alguns usuários carecia de qualquer postura crítica em relação aos pontos fortes e fracos dos programas. Os comentários geralmente se limitavam às características de CAQDAS referentes à tecnologia da informação. Para usar uma frase de Mackenzie (1990, 371), os 
entrevistados deste grupo eram os leais aos programas, aqueles que acreditam no que os manuais lhes dizem. Os usuários deste grupo também tinham menos probabilidades de abandonar o uso do programa adotado. Além disso, muitos entrevistados nesse grupo se referiram aos pacotes de CAQDAS como sendo 'meras ferramentas', como demonstra o exemplo abaixo:

CE: (...) como uma vez eu vi o 'programa $Y$ ' na sala de treinamento, minha impressão foi de que ele era exatamente o que eu precisava, alguma coisa para recortar e colar. A análise manual era um desperdício. Era uma perda de tempo. Também era politicamente incorreta, com todo aquele desperdício de papel. O programa me atraiu, era como um procedimento manual tornado mais fácil, simplesmente auxiliado por um programa, livrando você dos problemas da utilização de papel.

Inspirados pelas observações de Mackenzie e para facilitar os argumentos que se seguem, chamaremos este primeiro grupo de usuários 'leais'.

Se compararmos esse grupo de usuários com os diferentes tipos identificados por Lee e Fielding, é possível sugerir que o usuário 'leal' compartilha de muitas características do usuário 'ingênuo', sendo que a mais forte é a representação de CAQDAS como sendo, no fundo, um arquivo eletrônico.

Em contraste a descrição acima, a maioria dos usuários mais críticos se encontravam entre os pesquisadores da geração de mais idade ou com mais experiência, que já haviam trabalhado com programas CAQDAS diferentes Grupo 2 - e/ou haviam sido formados na 'tradição manual' - Grupo 3.

Estes usuários mais críticos interagiam com os programas comparativamente e expressavam altos níveis de consciência a respeito das questões metodológicas e epistemológicas em jogo. Os entrevistados desse grupo desenvolveram 'metanálise', enquanto trabalhavam com programas e, na verdade, foi entre os membros do Grupo 2 que encontramos ocorrências interessantes de 'reapropriação' criativa dos programas. Por essas razões, chamamos esse grupo de 'reflexivo'. 
A reapropriação de programas por parte de usuários reflexivos envolveu não apenas o exercício do pensamento crítico sobre as promessas apresentadas pelos programadores a respeito das capacidades do programa, mas também um uso criativo e inovador, o que revela uma compreensão e uma reflexão sobre o que o programa poderia fazer por seus dados, ao invés de ser o contrário.

Apresentamos duas ilustrações dos pensamentos de usuários 'reflexivos':

a) o usuário 'Jo' tem experiência com dois pacotes de CAQDAS e fez as seguintes observações:

Um ponto fraco do 'programa $X^{\prime}$ na minha opinião é que não há um delineamento claro entre as múltiplas análises que conseguimos obter usando o programa e o que aparece no texto final, quando descrevemos nossos resultados. Esta diferença não é muito clara. Tenho trabalhado como 'programa X'por muito tempo e este é o problema que eu tive. Deveria ser possível chegar a um mapa cognitivo, mas isso não se encontra lá.

A melhor maneira de utilizar o 'programa $X^{\prime}$ é para organizar dados, para a redução de textos de grande volume. Depois disso, deixe o pacote para lá e vá trabalhar com algum outro recurso. É um tipo de trabalho exploratório.

Isso é o que eu sempre pensei que seria genial de fazer (...) utilizar o 'programa X' para reduzir volume e gerar seu material fundamental e depois colocar no formato do 'programa $Y^{\prime}$ e fazer o trabalho interrogativo pesado. Deveríamos explorar opções criativas, ao invés de ficarmos em um só programa. O ideal seria usarmos diversos programas. 
Em outras palavras, o entrevistado foi capaz de articular que, apesar das promessas dos programadores de que o 'programa X' possibilita a construção de teoria, esta ocorreu em outro lugar, seja através do uso de outro programa ou simplesmente utilizando caneta e papel.

O entrevistado apresentou um desenho que mostra a diferença entre a alegada capacidade do 'programa $X^{\prime}$ e o que ele considerava que o programa era capaz de fazer. O desenho mostra também o que ele acredita ser necessário na análise de dados qualitativos e como este processo pode ser viabilizado, seja pelo uso de programas alternativos, seja através da análise manual.

\section{Drawing 1: By Interviewee}

'Programme X'

Index System
'Reappropriation:

User's Cognitive Map'

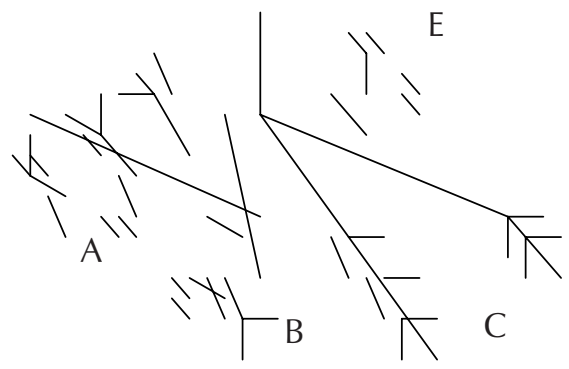

Data Reduction Exercise

Classification

Description

Hypotheses

Relationships between Codes A, B, C, D<smiles>[CH]=C</smiles>

Categories

Concepts about relationships<smiles>C=C[AsH2]</smiles>

Theory Building 
b) O usuário 'DA' tinha experiência anterior em análise manual de dados e experiência com o 'programa Z', desde o tempo em que trabalhou na Alemanha. Quando veio para o Centro com uma bolsa de pesquisa, foiIhe sugerido de forma incisiva que ela deveria utilizar o 'programa $X$ ' para analisar seus dados sobre "A Mulher e Ciclos de Vida após a Segunda Guerra Mundial". Ela tentou aprender o programa, utilizou-o até certo ponto e depois o abandonou.

As pessoas estão convencidas de que este programa é muito bom. Eeu não conhecia nada além do 'programa $Z$ ', apenas a codificação, ao passo que o 'programa $X$ ' possibilitava a codificação de segmentos de texto na tela. Pensei: tudo bem (...) mas acho que fiquei cética por causa da estrutura de árvore, eu não gostava muito e tenho uma sensação de que o 'programa X' é muito hierárquico, você começa pelo quadro geral, ... a idéia de que ele funciona com hierarquias. Eu queria trabalhar com dicotomias, (...) Eu usei o Word Perfect no final, utilizando os comandos 'buscar e localizar'. Eu precisava manter os códigos em contexto. Eu estava sob pressão e queria ir adiante com meu trabalho."

Embora 'DA' tenha dito que talvez volte a usar o 'programa $\mathrm{X}$ ' devido ao grande número de casos que tem para analisar (102), ela também disse que, se fosse o caso, usaria o sistema de codificação, mas não a estrutura de árvore.

Na verdade, pode-se sugerir que o uso seletivo de recursos nos programas parece ser uma forma muito interessante de exercer flexibilidade interpretativa. Entretanto, dada a forma como o mercado de CAQDAS se desen- 
volveu e, apesar de solicitações por parte de usuários, os programas não têm uma plataforma comum que permita um movimento fácil e rápido entre os pacotes.

Muitos debates sobre este tema apareceram nos grupos de discussão de CAQDAS, às vezes sob o nome de 'a necessidade de uma plataforma comum para CAQDAS'. Esta questão tem sido debatida de forma inflamada por alguns programadores e muitos usuários. Outro tema debatido animadamente é a respeito da justificação ou não da crescente complexidade de recursos dos programas. As discussões sobre esta última questão têm acontecido sob o nome de 'sinos e apitos' ( $\mathrm{N}$. de T). A entrevistada chamada 'DA' apresenta uma opinião muito clara sobre isso, ao fazer a seguinte observação:

Parece-me que estes programas poderiam ser muito mais simples do que são, ou seja, conhecendo um pouco do 'programa X'e tendo dado uma olhada no 'programa $Y$ ', são nítidas as tantas coisas que eles podem fazer além do que é necessário. Eu gostaria de uma versão menos complexa dos programas, uma versão mais simples tornaria a vida um pouco mais fácil.

O Grupo 3 é formado pela geração mais velha, que tem experiência prévia com a análise manual de dados mas, ao mesmo tempo, adquiriu suas habilidades em computadores muito mais tarde, quando comparado aos pós-graduandos mais jovens. Chamaremos este grupo de 'qualitativista experiente'. Quanto mais velho o usuário, mais hesitante parece ser a interação com os computadores e programas. Se, por um lado, esses usuários têm menos habilidades no desenvolvimento de suas próprias estratégias para a superação de problemas técnicos, em qualquer das fases de utilização, parece haver, por outro lado, um maior grau de pensamento reflexivo e crítico sobre seu uso. Isso é evidente, por exemplo, ao refletirmos sobre as implicações do que um dos entrevistados (o usuário GE) chamou 
de trabalhar dentro de uma estrutura imposta.

É uma coisa que passou pela minha cabeça mesmo antes de trabalhar com o 'programa $Y$ '. Porque se volta à questão da estrutura que você está impondo a seus dados. Suponho que, com o 'programa $Y$ ', haja apenas uma certa quantidade de opções, há apenas certos lugares para onde se pode ir, não é infinito, nem se esperaria que fosse. Então, isso me preocupa, pois irá para um certo caminho, inevitavelmente.

A reflexão acima aponta para a importância do fato de que a experiência anterior como pesquisador que desenvolve trabalho qualitativo, bem como com outros pacotes de CAQDAS, influenciou o uso deste artefato tecnológico específico. Parece que, quanto mais complexa a estrutura comparativa que se tem à disposição, em relação ao nível de conhecimento e metodologia, experiência na análise de dados qualitativos, bem como prática em diferentes pacotes de CAQDAS, maiores as chances para flexibilidade interpretativa.

Em resumo, os três grupos apresentados aqui, o 'leal', o 'reflexivo' e o 'qualitativista experiente', ocupam posições muito diferentes em relação às percepções de certeza/incerteza sobre CAQDAS, como explicamos abaixo.

\section{A 'curva de certeza': a distribuição de certeza nos grupos de usuários de CAQDAS}

Mackenzie (1990) e Woolgar (1994) apontaram para o fato de que a percepção da eficácia de uma tecnologia e seus padrões resultantes de aceitabilidade ou rejeição estão relacionados com a distribuição de certezas sobre o artefato. Essa idéia pode ser ilustrada pela 'curva de certeza'. O eixo 
horizontal mostra proximidade e distanciamento do local de produção, bem como da comunidade de usuários. O eixo vertical registra os níveis de incerteza. A curva representa a distribuição de certeza/incerteza sobre tecnologia, dentro dos grupos. Isso inclui os programadores e os diferentes tipos de consumidores.

Os 'usuários configurados' (Woolgar 1996) , os que foram seduzidos e alistados, tenderão a apresentar níveis relativamente baixos de incerteza e ocupar a 'curva de certeza'. Os que estão distantes do local de produção tenderão a mostrar níveis altos de incerteza. Estes níveis tendem a aumentar ainda mais, à medida que nos afastamos do local de produção.

A pesquisa de Mackenzie sobre precisão de mísseis proporcionou uma contribuição teórica criativa ao mostrar que, ao contrário do esperado, aqueles que estão próximos ao local de produção, os produtores, também tenderam a mostrar altos níveis de incerteza sobre a tecnologia.

\section{Figura 2: A 'Curva da Certeza' \\ (Mackenzie 1990 e Woolgar 1994)}

INCERTEZA

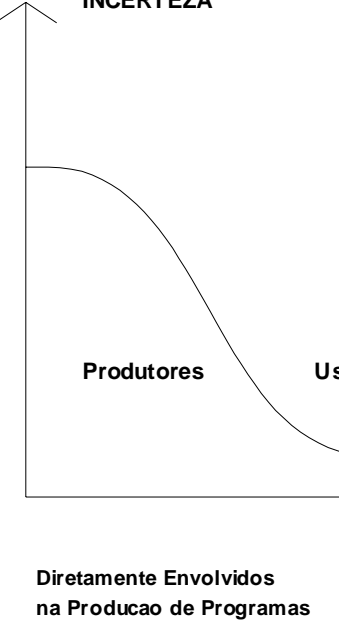

Usuarios Configurados

Usuarios nao Configurados 
Se aplicarmos essas idéias à comunidade de CAQDAS e trouxermos diferentes grupos de usuários identificados nas seções 1 e 2 deste artigo, a distribuição se modifica significativamente. Como demonstramos abaixo, a representação gráfica da distribuição não é mais uma curva, mas uma representação gráfica diferente.

\section{Figura 3: O 'Diagrama da Certeza' A Comunidade CAQDAS}

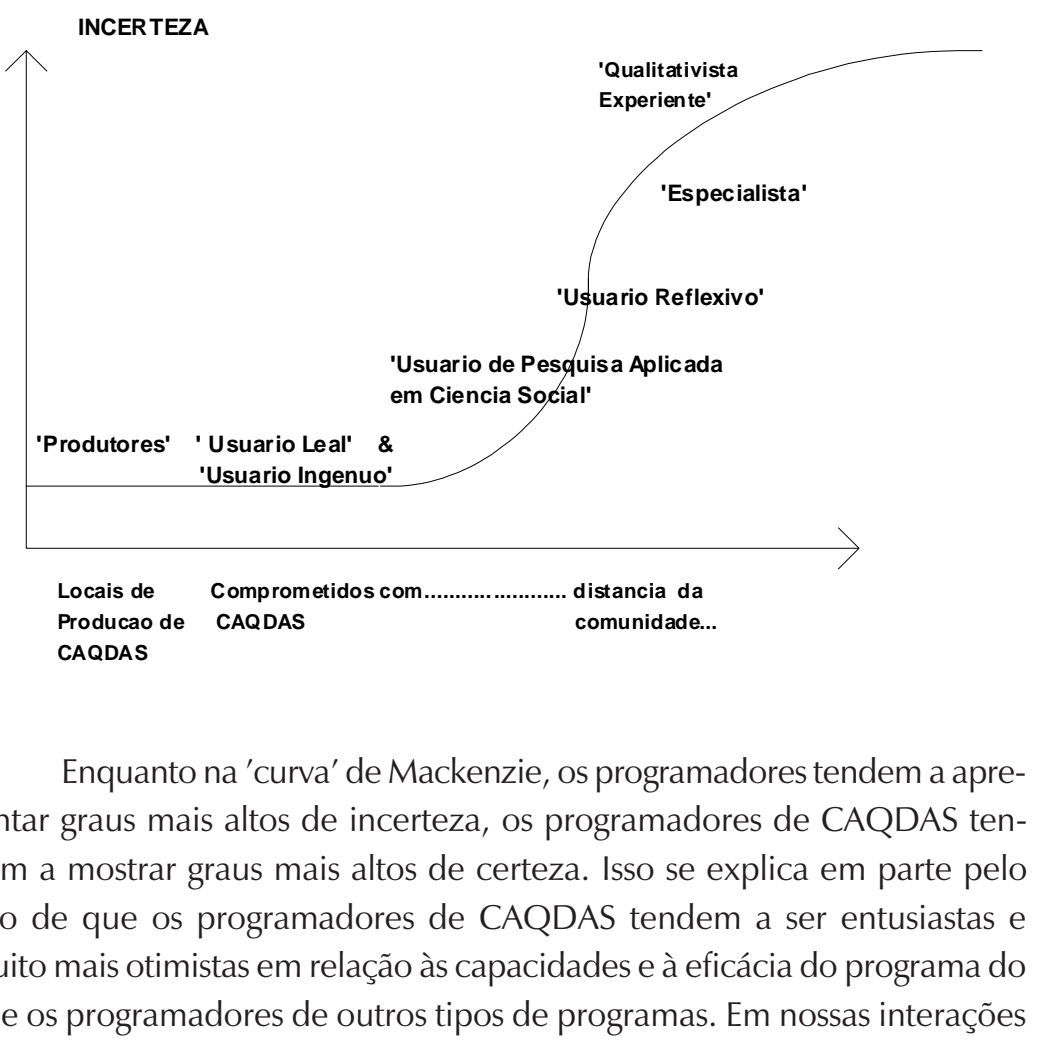


com eles durante os anos, não conseguimos identificar o que Mackenzie (1990:371) descreveu como a presença de dúvidas de natureza mais privada e mais limitada, mas bastante reais.

Isso pode ser explicado por uma referência à história específica das origens de CAQDAS. Os programas foram o resultado da experiência dos próprios programadores, que eram pesquisadores qualitativos, que criaram programas como uma resposta a necessidades específicas de pesquisa. Devido a este duplo papel de cientista social/designerde programas, há um forte pressuposto subjacente, o de que eles sabem o que é necessário em um pacote de CAQDAS. Além disso, segundo eles, uma vez que os defeitos tenham sido controlados e eliminados, estes pacotes têm capacidade de dar assistência na análise de dados qualitativos.

Esta história também permite que os programadores utilizem o argumento de autoridade, que deriva do fato de que eles utilizaram os pacotes CAQDAS em seu próprio trabalho de pesquisa e "funcionou". Isso dá origem a um tipo específico de configuração de usuário, já que é precisamente o limite indefinido entre programadores e usuários que dá aos pacotes sua utilidade, atratividade e credibilidade. Os programadores trabalham ativamente com a idéia de que produziram programas para 'seus colegas'.

Com relação aos três grupos de usuários identificados por Mangabeira - os 'leais', os 'reflexivos' e os 'qualitativistas experientes', a distribuição de certeza é a seguinte: como esperado, os 'leais' parecem expressar o mais alto grau de otimismo em relação à eficácia do programa e o menor grau de incerteza, sendo, na linguagem de Woolgar (1996), os 'usuários configurados'.

O grau de incerteza tende a aumentar à medida que nos afastamos do centro de produção de programas e/ou da comunidade CAQDAS. Se observamos a localização dos 'reflexivos' e dos 'qualitativistas experientes', verificamos que os usuários neste último grupo parecem ser os mais céticos com relação à eficácia dos programas; os 'reflexivos', por contraste, muito mais ligados á comunidade CAQDAS, apresentam graus menores de certeza do que os 'leais' e, ainda assim, exibem otimismo a respeito do potencial de CAQDAS. 
Podemos também levantar a hipótese, dadas as conclusões da pesquisa de Lee e Fielding sobre os usuários, de que o grupo que eles chamaram de usuário ingênuo' ocupa a mesma posição dos usuários 'leais' de Mangabeira na figura 3. Da mesma forma, o grupo de 'especialistas' de Lee e Fielding apresenta representações sobre o potencial de CAQDAS, semeIhantes às do 'reflexivo' e do 'qualitativista experiente' na etnografia de Mangabeira. No entanto, como o 'especialista' está ligado muito mais fortemente à comunidade CAQDAS do que o 'qualitativista experiente', esses grupos ocupam posições diferentes no 'diagrama da certeza'.

\section{Conclusão}

À medida que CAQDAS encontra novas aplicações e usuários, é possível observar uma discrepância cada vez maior entre as suposições sobre os usos que são feitos por programadores e padrões reais de uso. Quando o uso estava limitado, em grande parte, a um pequeno círculo de entusiastas e aos usuários de primeira geração, era mais simples identificar as necessidades dos usuários e entender os processos sociais que facilitavam e /ou inibiam a adoção de programas.

Se tomamos as conclusões apresentadas neste artigo e projetamos os padrões de adoção no futuro, baseados no 'diagrama da certeza', é possível sugerir que o maior crescimento nos números de usuários de CAQDAS tenderá a acontecer entre a geração mais jovem de Cientistas Sociais, bem como entre o novo grupo de usuários na pesquisa aplicada. Se este for o caso, a acentuação da tendência da abordagem de uso instrumental dos programas, como 'mera ferramenta', irá colocar novos desafios para o futuro, especialmente para dois grupos de usuários de CAQDAS.

O primeiro grupo é composto pelos programadores, que podem precisar distanciar-se de suas origens 'qualitativistas', acentuando ainda mais a versatilidade de seus programas, ao invés do uso específico. Eles precisa- 
rão encontrar um equilíbrio na tênue linha divisória entre manter seu apoio e aliança com a comunidade dos que desenvolvem trabalhos qualitativos e o meio acadêmico, que são suas fontes de credibilidade e legitimidade e, ao mesmo tempo, expandir suas atividades comerciais, que acontecem muito distantes destes locais.

Os integrantes do segundo grupos - os cientistas sociais experientes - podem ter que sentar-se impacientemente e observar a reapropriação, por parte de usuários 'ingênuos', de uma tecnologia que estava originalmente ligada a uma disciplina acadêmica específica. Como já foi dito, se estes usuários aprenderem os programas de forma isolada de uma apreciação do método qualitativo, há um risco de que os recursos analíticos nos pacotes escolhidos por eles passem a ser vistos como 'análise qualitativa'. Resumindo, sua apreciação do método qualitativo torna-se limitada e definida pelo programa adotado.

Dado este quadro, o desafio para os cientistas sociais qualitativos experientes, que são entusiastas de CAQDAS, deveria ser o de educar através do treinamento nos programas, difusão de informações e canais de ajuda -, combatendo, assim, a tendência no sentido da estabilização de um ou dois pacotes comercialmente bem-sucedidos, às custas de outros. Isso ajudaria a salvaguardar, ainda que de forma indireta, a pluralidade das abordagens qualitativas e estilos analíticos.

\section{Referências Bibliográficas}

ABBOTT, A. 'The causal devolution', Sociological Methods and Research, 27:(2) 148-181. 1998.

ALLATT P. and BENSON, L. 'Computing and qualitative analysis: issues in research methods teaching', in N. Fielding and R. Lee, eds., Using computers in qualitative research, London: Sage. 1991. 
COOPER, G. HINE, C. LOW, L and WOOLGAR, S. 'Ethnography and Human Computer Interaction'. CRICT Discussion Paper, No. 39. September. 1993.

FIELDING, N. and LEE, R. 'Diffusion of a methodological innovation: Computerassisted qualitative data analysis in the UK', in Mangabeira ed., Current Sociology, 44(3), :242-58. 1996.

FIELDING, N. and LEE, R. Computer Analysis and Qualitative Research, London: Sage. 1998.

GEERTZ, C. Local Knowldge: Further Essays in Interpretative Anthropology, New York: Basic Books. 1986.

GRINT, K. and WOOLGAR, S. 'Computers, Guns and Roses: What's Social About Being Shot?' in Science, Technology and Human Values, 17 (3). 1992.

HINE, C. 'Virtual Ethnography'. CRICT Discussion Paper, No 43. May.1994.

KELLE, U. ed., Computer-aided qualitative data analysis: theory, methods and practice, London: Sage. 1995.

MACKENZIE, D. Inventing Accuracy. A Historical Sociology of Nuclear Guidance, Cambridge, MA: MIT Press. 1990.

MANGABEIRA, W. C. 'Computer assistance, qualitative analysis and model building', in R.M. Lee, ed., Information Technology for the social scientist, London: UCL Press. 1995.

MANGABEIRA, W. C. 'Qualitative Analysis and Microcomputer Software: Some Reflections on a New Trend in Sociological Research', in R. G. Burgess, ed., Qualitative Methodology, London: Jai Press. 1995. 
MANGABEIRA, W.C. (ed.) Qualitative Sociology and Computer Programs: Advent and Diffusion of CAQDAS, London: Sage Publications. 1996.

WOOLGAR, S. Rethinking the Dissemination of Science and Technology. CRICT Discussion Paper. No. 44. May. 1994.

WOOLGAR, S. 'Configuring the User: the case of usability trials', in J. Law (ed.) A Sociology of Monsters: Essays on Power, Technology and Domination, pp. 57-99. London: Routledge. 1994.

\section{Resumo}

Esse artigo coloca em debate as transformações ocorridas no uso do programa assistente para análise qualitativa de dados (CAQDAS) desde a década de setenta abordando, especialmente a utilização diferenciada dessa tecnologia por parte de diferentes tipos e gerações de usuários.

Palavras-chave: tecnologias informacionais, Pesquisa qualitativa, CAQDAS, NUDIST. 